\title{
A EXPERIÊNCIA DE AVALIAÇÃo EDUCACIONAL EM MINAS GERAIS: 1992 A 1998
}

\author{
MARIA ALBA DE SOUZA ${ }^{1}$ \\ $\hat{E}$ isto que uma árvore é. \\ Um simples momento de beleza.
}

\section{Introdução}

No Brasil, as profundas transformaçōes políticas da última década, com a instalação do processo democrático de participação social, a definiçăo de co-responsabilidades na área da educação, o aumento do nível de exigência de uma sociedade cada vez mais organizada e consciente dos seus direitos, tornaram indispensável o reexame de muitos valores, especialmente aqueles que sustentam a elaboraçăo de um projeto de Escola compatível com essa nova realidade.

A reflexăo em torno desses aspectos coloca a avaliação educacional em uma posiçăo central, uma vez que justamente a avaliação é o ponto de referência para introdução de processos de mudança e inovação servindo de base para superação dos grandes desafios da qualidade, da eficiência, da eficácia e da responsabilidade social.

A avaliação no contexto educacional brasileiro é quase sempre promovida por órgãos governamentais: no âmbito federal, pelo Ministério da Educação, no estadual, pelas Secretaria de Estado.

O modelo apresentado neste documento refere-se ao Programa de Avaliação da Escola Pública de Minas Gerais, no período de 1992 a 1998.

- Diretora da DAVE/CEAVE - Centro de Qualidade de Avaliaçăo e Informaçăo Educacional da Secretaria de Estado da Educaçâo de Minas Gerais, no perfodo de 1992 a 1998 
A partir do início da década de 90, o estado de Minas Gerais vem enfrentando o desafio de melhorar a qualidade do ensino oferecido pela escolas públicas estaduais. Desde entảo já se percebe que a melhoria da qualidade da educação năo se constitui em meta que possa ser alcançada em curto prazo, nem em fórmulas mágicas que se orientem para ações isoladas. Foi-se firmando, então, a idéia de que a instalação e o desenvolvimento de uma política de qualidade na Educação pressupōem a existência de um sistema de avaliação que, num primeiro momento, proporcione o conhecimento do sistema educacional que se quer melhor $\mathrm{e}$, em seguida, passe a avaliar regularmente o seu desempenho.

Há também que se referir ao fato de que a busca da qualidade da educação na Escola pública tem sido um reflexo da necessidade sentida pela sociedade e comunidades. Os governantes, além de estarem atentos para incorporar, em suas formulaçōes políticas e pragmáticas, essas legítimas demandas, tiveram que se preparar para estarem aptos a informar essa mesma sociedade sobre o desempenho das escolas públicas que ela utiliza e custeia.

A decisāo política de avaliar o sistema resultou do conhecimento e da vivência dos principais problemas desse sistema, assim como de uma análise crítica e isenta dos seus vários aspectos. A partir da identificaçăo dos agentes da educaçăo - o aluno, os pais ou os responsáveis pelo aluno, o profissional da educação (professor, especialista, funcionário, serviçal) e a Escola - foram estabelecidos compromissos com esses agentes, nos quais se evidenciou todo o processo educacional no Estado:

1. autonomia da Escola;

2. fortalecimento da direçāo da Escola;

3. aperfeiçoamento e capacitação dos profissionais;

4. avaliação do Sistema Estadual de Educação;

5. integração com os municípios do Estado.

Dentro dessas diretrizes políticas, a avaliação do sistema educacional do Estado foi enfocada como elemento básico e instrumento fundamental para o conhecimento da realidade 
educacional, para identificação dos pontos críticos e, consequentemente para a melhoria, a implementaçāo e o acompanhamento das açōes necessárias para se atingir a qualidade na educação.

A avaliação sistemática das escolas, impôs, assim, como condição indispensável à conquista da autonomia, sobretudo pedagógica, na medida em que, a partir do conhecimento da sua realidade educacional, teriam as escolas que assumir responsabilidade e compromisso pelo ensino ministrado e pela prestação de contas à sociedade a que servem.

Firmou-se ainda o "consenso de que é preciso criar mecanismos de avaliaçāo e de prestaçāo de contas, ou seja, começarmos a construir uma cultura avaliativa". (Mello, 96).

A questão da qualidade da educação e sua avaliação ficou definida na Constituição do Estado de Minas Gerais (1989), que, no seu artigo 196, item X, estabeleceu como uma das condiçōes para garantir o padrāo de qualidade do ensino "a avaliaçăo cooperativa periódica por órgão do sistema educacional, pelo corpo docente e pelos responsáveis pelos alunos".

Assim, com o respaldo da Constituição do Estado, a decisão política de avaliar a qualidade do ensino e a sensibilização de todos os segmentos da sociedade determinaram o início do Programa de Avaliação da Escola Pública de Minas Gerais.

Hoje, a Lei Federal $n^{\circ}$ 9394/96 Nova Lei de Diretrizes e Bases da Educação Nacional, também, já preconiza em seu artigo $9^{\circ}, \mathrm{VI}$, que: "inclusive a Uniăo organize processo nacional de avaliação do rendimento escolar para todos os níveis de ensino, objetivando a definição de prioridades e a melhoria da qualidade do ensino". Assim este programa, pioneiro no Brasil, tornou-se uma referencia nacional, integrando o panorama educacional brasileiro.

O programa de avaliaçăo desenvolvido no Estado de Minas Gerais nesse período promoveu três ciclos de provas ( 1992, 1994, 1996), com ampla divulgação e utilização dos resultados, constituindo um marco importante no conjunto das mudanças ocorridas na rede estadual de ensino. 
Os três ciclos realizados revelaram uma crescente melhoria dos alunos, das condiçōes de trabalho e da qualidade do ensino, o que permitiu ao sistema ousar mais e propor transformações, conforme o quadro Aspectos Diferenciadores, anexo a este documento.

Em 1997, foram realizadas avaliaçöes especiais com o objetivo de determinar o nível de progresso dos alunos incluídos em Programa Emergencial do Ciclo Básico de Alfabetização $\mathrm{CBA}$, e ainda determinar o efeito de eventuais intervenções com alunos de risco da quarta série do Ensino Fundamental. Estas avaliaçōes foram realizadas pelo Instituto Internacional de Avaliação Sérgio Costa Ribeiro que contou com a parceria do $A C T$ - American College Testing, uma das mais renomadas instituiçōes de avaliação dos Estados Unidos.

A partir de 1998, com a implantação do Regime de Progressão Continuada no Ensino Fundamental e sua organizaçāo em dois ciclos de formação básica nas escolas públicas estaduais, a avaliação sistêmica sofreu uma mudança fundamental quanto à metodologia.

As avaliaçōes que eram realizadas a cada dois anos, passariam a ser oferecidas anualmente, dentro de uma nova perspectiva metodológica, procurando adequar-se ao Regime de Progressão Continuada, com a utilização de metodologias mais avançadas que possibilitassem verificar se o aluno atingiu um determinado padrão de desempenho. - Ver quadro anexo.

A avaliação sistêmica trata, a partir de então, de maniter professores e escolas informados dos efeitos sobre o rendimento e o desenvolvimento dos alunos como conseqüência da implementaçāo das novas medidas adotadas e de informar a todos a respeito dos progressos alcançados e das dificuldades a serem superadas.

Esse sistema de avaliação estaria permitindo à Secretaria, às escolas, aos professores e aos especialistas dispor de um painel diagnóstico preciso e confiável a respeito da educaçăo no Estado de Minas Gerais e, mais especificamente, de dados válidos referentes ao rendimento escolar, permitindo um ajuste mais 
adequado das estratégias pedagógicas e dos métodos de ensino às características e necessidades dos alunos.

\section{O Esboço do Programa}

\subsection{Fundamentos}

Fundamentaram a instituição do mencionado Programa de Avaliação as seguintes evidências e argumentos, dentre outros:

$>$ havia compromisso expresso do Governo e da Secretaria de Educação de propiciar as condições necessárias para a construçăo de uma Escola pública autônoma e de qualidade;

$>$ era importante estabelecer-se uma cultura avaliativa preocupada com problemas de relevância para o ensino;

$>$ havia necessidade de se resgatar a funçăo do "ensino', centrando a atuaçāo da Escola na satisfação das necessidades básicas de aprendizagem para todos;

havia urgência na produçăo de informações sobre escolas, regiōes e população específicas que orientassem a formulação de programas de compensação ou discriminação positiva para atendimento a dificuldades evidenciadas;

$>$ era imprescindível produzir informaçōes que subsidiassem o estabelecimento de políticas de desenvolvimento de recursos humanos e de adequadas estruturas curriculares;

havia interesse em se informar a sociedade e a comunidade educacional sobre o desempenho das escolas estaduais;

$>$ era relevante fundamentar decisōes que objetivassem melhoria na administração do sistema educacional, em resultados avaliativos cientificamente apurados.

\subsection{Objetivos}

\subsubsection{Para que avaliar?}

Os objetivos do Programa de Avaliação abrangeram quatro aspectos que caracterizaram os propósitos de uma avaliaçăo institucional tendo em vista a qualidade do ensino nas escolas estaduais: 
a) conhecer o desempenho dos alunos em aspectos cognitivos dos conteúdos curriculares;

b) levantar dados e informações para servirem de subsídios na tomada de decisões sobre o desenvolvimento do processo de ensino;

c) identificar, nos conteúdos curriculares, pontos críticos que necessitam maior atenção e requerem intervenção imediata e prioritária para a melhoria da aprendizagem;

d) fornecer, a partir dos dados levantados, subsídios para que os professores possam atuar com maior eficiência na conduçăo do processo de ensino, e a Secretaria de Educaçăo possa colaborar para maior eficiência do sistema.

Em síntese, este Programa de Avaliação da Escola Pública objetivou realizar diagnóstico e compor acervo de dados e informaçōes consistentes sobre as escolas, com vistas a obter uma base importante para implementação de um plano de melhoria do ensino que viesse a intervir na baixa produtividade do sistema e nos elevados índices de retenção dos alunos, sobretudo nas séries iniciais do Ensino Fundamental.

$\mathrm{Na}$ atual concepção do Programa a Escola passa também a receber informaçōes específicas de cada turma e de cada aluno.

\section{Estrutura do Programa}

O Programa de Avaliação da Escola Pública de Minas Gerais abrangeu todos os municípios do estado, hoje 853 , as 41 Superintendências Regionais e a Capital, todas as Escolas Estaduais que ofereciam as séries a serem avaliadas e todos os alunos pertencentes a essas séries, num total de 1.946.342, nos três primeiros ciclos de avaliação.

Optou-se por uma avaliação censitária, isto é, envolvendo toda a população de alunos das séries escolares a serem avaliadas, com intenção de: 
$\left.1^{9}\right)$ criar uma cultura de avaliação em todo o sistema, considerando que a prática avaliativa é bastante episódica na Escola. A exclusão de alunos e escolas, possivelmente, năo geraria um maior comprometimento dos professores;

$2^{9}$ influenciar, através dos instrumentos utilizados (provas), a qualidade das práticas avaliativas que cada Escola usa, bastante precárias em muitas escolas de diferentes regiôes;

$\left.3^{\circ}\right)$ possibilitar que todas as escolas, professores e seus alunos realizem uma auto-avaliaçāo, comparando os resultados da sua Escola com os de outros municípios da região e do Estado;

$\left.4^{\circ}\right)$ levar os professores a uma atividade cooperativa dentro da própria Escola e com membros integrantes do Colegiado da Escola, que, segundo as normas estabelecidas, também, sempre participaram da avaliação, atuando, todos, no controle do ensino de qualidade e elaborando relatórios de avaliaçăo;

$5^{\circ}$ ) identificar as escolas que, face às deficiências constatadas, necessitavam de assistência que thes garantissem condiçōes materiais e de aprimoramento de seus recursos humanos;

$\left.6^{\circ}\right)$ positivar, no conjunto do sistema, as escolas de melhor desempenho a fim de que seus professores e demais participantes do processo educativo pudessem ter o seu mérito reconhecido; e, finalmente,

$\left.7^{\circ}\right)$ permitir que as opçōes avaliativas propostas no Programa de Avaliação contribuíssem, efetivamente, para que todas as escolas alcançassem sua autonomia, sobretudo pedagógica.

Embora todos os alunos da série escolar selecionada tenham sido submetidos à avaliaçăo, cada um deles respondeu a apenas uma das provas constantes da avaliação, tendo sido adotada uma enturmação específica para determinar qual prova cada aluno faria.

As séries escolares selecionadas para a Avaliação, que ocorreria sistematicamente a cada dois anos, representavam término de ciclo ou de grau de ensino: 
- início da $3^{a}$ série do Ensino Fundamental - alunos egressos do Ciclo Básico de Alfabetização;

- $5^{a}$ série do Ensino Fundamental - série em que o aluno passa por mudanças na sua vida escolar, pessoal, etc.;

- $8^{a}$ série do Ensino do Ensino Fundamental - término do Ensino Fundamental;

- $2^{a}$ série do Ensino Médio - quando o aluno ainda não participa de cursos preparatórios para o vestibular;

- série concluinte do Curso de Habilitação para o Magistério (Professor de $1^{\text {a a }} 4^{a}$ Série do $1^{\circ} \mathrm{Grau}$ - alunos futuros professores que irão atuar nas quatro primeiras séries do Ensino Fundamental.

A decisão de se avaliar o rendimento do aluno das séries selecionadas a cada dois anos objetivou permitir que entre uma avaliaçāo e outra houvesse tempo suficiente para que medidas de intervenção ocorressem para sanar as deficiências diagnosticadas.

Em 1998, com a implantação do regime de progressãocontinuada e sua organizaçāo em ciclos de formação básica no estado de Minas Gerais a manutenção do programa de avaliação sistêmica torna-se ainda mais importante e passa a ser realizada no final desses ciclos.

Convém ressaltar a participação dos alunos, das escolas Públicas Municipais cujas prefeituras, em quase sua totalidade, reconhecendo a importância do programa de avaliaçăo que vinha sendo desenvolvido no Estado, atenderam ao convite da Secretaria de Estado da Educaçāo e aderiram ao referido Programa.

\section{Desenvolvimento do Programa}

Para a implementação do Programa de Avaliação do Sistema Educacional, e Secretaria de Educação de Minas Gerais criou a Diretoria de Avaliação de Ensino - DAVE - órgăo 
responsável pelo gerenciamento de todas as atividades ligadas ao Programa.

O desenvolvimento do Programa e sua interligaçăo com a área de informaçōes educacionais acabaram tornando oportuno o redimensionamento da DAVE que foi substituída pelo Centro de Qualidade de avaliação e Informação Educacional - CEAVE garantindo maior autonomia ao sistema de avaliação e criando melhores condiçōes para sua operacionalização.

Ligado diretamente ao gabinete do Secretário de Educação, - CEAVE passou a ter mais agilidade e respaldo para a tomada de decisōes.

Nessa perspectiva coube ao setor, em conjunto com órgãos superiores da SEE/MG, estabelecer políticas de avaliaçāo, de modo a atender às necessidades do sistema estadual de educação, tendo em vista o relacionamento deste com a realidade econômica, política e social do Estado e do País.

Coube ainda ao CEAVE, o papel de articular os segmentos de ensino para a implementação das referidas políticas e estimular, cada vez mais, o desenvolvimento de uma cultura de avaliação que resultasse no uso sistemático dos seus resultados como ferramenta de gerência do sistema estadúal de educaçāo e da gestão democrática da Escola.

Nesse contexto, a DAVE/CEAVE sempre desempenhou importante papel na integraçăo dos três níveis - central (SEE), regional (SRE) e local (escolas) - que constituem a estrutura do sistema estadual de educação, de forma que o impacto do Programa de Avaliação da Escola Pública de Minas Gerais atingisse efetivamente as escolas e cumprisse sua finalidade precípua de contribuir para a oferta de uma educaçāo básica de qualidade para toda a população do Estado.

A complexidade do processo de avaliação do sistema educacional exigiu a utilização de serviços técnicos especializados, tais como: 
- impressão de centenas de milhares de provas, manuais de orientação e materiais de divulgaçăo por órgão do Estado - a Imprensa oficial;

- cadastramento de escolas, divisão do alunado em turmas e por disciplina, identificação das Folhas de Respostas, processamento dos dados coletados e emissão de estatísticas por meio da PRODEMGE - Companhia de Processamento de Dados do Estado de Minas Gerais;

- mixagem e distribuição dos testes, questionários, relatórios e manuais de orientação pela Empresa de Correio e Telégrafos - ECT;

- leitura ótica das folhas de respostas, pelo Centro de Computação - CECOM - da UFMG.

O Programa de Avaliação de Minas Gerais também contou com uma consultoria externa contratada a qual se responsabilizou pela condução dos aspectos teóricos e metodológicos da avaliaçăo, cujo consultor técnico foi Heraldo Marelim Vianna, pesquisador Senior da Fundação Carlos Chagas, de Săo Paulo e especialista em Avaliaçăo Educacional.

Tendo em vista o propósito de se desenvolver uma cultura institucional de avaliação na SEE/MG e na rede estadual de ensino, foi fundamental a criaçăo de oportunidades de aperfeiçoamento profissional para os integrantes do órgāo central e Superintendências Regionais de Ensino, de modo a ampliar e aprofundar a competência técnica no Campo da Avaliação Educacional.

Nesse intuito, vários cursos foram organizados pela DAVE/CEAVE: 


\begin{tabular}{|c|c|c|c|}
\hline CURSO & $\begin{array}{l}\text { M!S! } \\
\text { ANO }\end{array}$ & $\begin{array}{c}\text { CARCA } \\
\text { HOKAKIA }\end{array}$ & DOCENTE \\
\hline A valiscicto Eftec acinnat & abritia & 112 Mets!t5 & Prof. Heraluo Mardinal Viant?a \\
\hline Estatística & $\begin{array}{l}\text { mail } 95 \text { a } \\
\text { mai/ } / 96\end{array}$ & 80 horas & Prof. José Xisto Barros \\
\hline $\begin{array}{l}\text { Medidas com Referência a } \\
\text { critérios (dois módulos) }\end{array}$ & $\begin{array}{l}\text { Nov/95 } \\
\text { out/97 }\end{array}$ & 80 horas & $\begin{array}{l}\text { Prof. Juan Manuel Esquivel } \\
\text { Alfaro }\end{array}$ \\
\hline $\begin{array}{l}\text { Avaliação Educacional - } \\
\text { As grandes linhas }\end{array}$ & Dez/96 & 40 horas & Prof. Heraldo Marelim Vianna \\
\hline $\begin{array}{l}\text { Avaliação Educacional - } \\
\text { Diferentes metodologias } \\
\text { (dois módulos) }\end{array}$ & $\begin{array}{l}\operatorname{mar} / 97 \\
\mathrm{jun} / 97\end{array}$ & 24 horas & Prof. Heraldo Marelim Vianna \\
\hline $\begin{array}{c}\text { Técnicas para elaboração } \\
\text { de Questionários }\end{array}$ & abril/97 & 16 horas & Prof ${ }^{3}$ Maria Luiza Costa Ferraz \\
\hline $\begin{array}{l}\text { Fundamentos de Aval iaçāo } \\
\text { de J'extos }\end{array}$ & ristiplob & 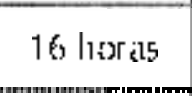 & 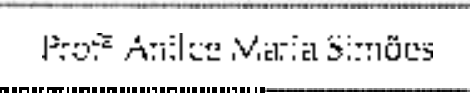 \\
\hline $\begin{array}{l}\text { Avaliaçāo de Desempenho } \\
\text { Escolar baseado em } \\
\text { Critérios. ( } 3 \text { módulos) }\end{array}$ & $\begin{array}{l}\mathrm{abr} / j \mathrm{jl} / \\
\mathrm{nov} / 98\end{array}$ & 120 horas & \\
\hline
\end{tabular}

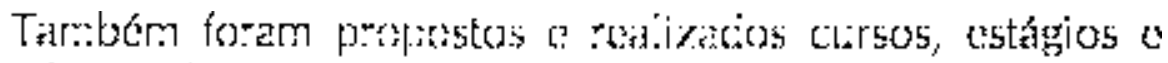

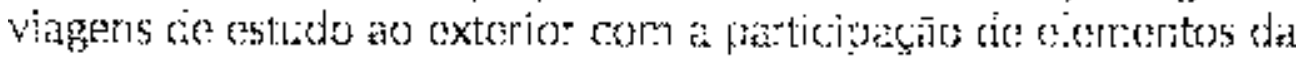

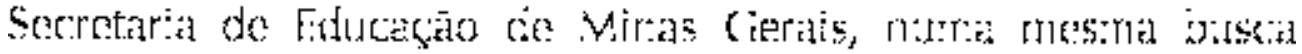
corstarite de aportecowamento tais como:

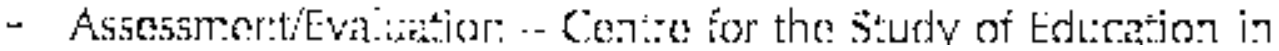
a International Context .... CEIC .... Univesity of Bath .... United Kingdon .... 1993.

- Developing a National Assessment Program - Educational Testing Service -... ETS - Princeton -... USA .... 1993.

* Evaluacion del Processe Educativo ... Secretaria de Education Publica - México -... 1994.

* Intermational Evaluation Conference ... Vancouver ... Cartadá 1995.

- Study Tour, con visitas a Instituiçóes de Avaliaçá, na França, Inglaterra, Suécia e Holanda lorganizaçäo do MEC/BR - 1996. 
- Study Tour, com visitas a escolas, órgåos oficiais e Instituiçōes de Avaliação, na Austrália e Nova Zelândia (promoção do Banco Mundial) - 1998.

- Study Tour e participação no "Annual Forum and Summer Data Conference" - Washington/DC - USA - (coordenação do AIR - American Institutes for Research - USA) - 1998.

\section{Instrumentos de Avaliação}

\subsection{Três instrumentos básicos foram utilizados para a pesquisa do rendimento escolar:}

$\checkmark$ as provas de caráter objetivo, procuram verificar, basicamente, três capacidades: conhecimento, compreensão e uso do conhecimento. Também uma prova de redaçăo é exigida com vistas a estabelecer em que medida os alunos possuem capacidade de expressăo escrita. Para a elaboraçăo dessas provas, a participaçăo de professores com experiência em sala de aula e atuantes no ensino das diversas disciplinas é fundamental.

$\checkmark$ o questionário da Escola contendo questōes cujas respostas possibilitam reunir informações gerais sobre o seu funcionamento, o seu corpo docente, os seus procedimentos relativos a organização administrativa, liderança e condução pedagógica. As informaçōes são fornecidas pela direçăo, pelos representantes do colegiado, pelos especialistas e docentes da Escola, mediante consenso.

$\checkmark$ o Questionário do Aluno contendo itens que levam a obter informaçōes consideradas de relevada importância para conhecimento da realidade do aluno, tais como, seus dados pessoais, seus hábitos escolares, suas pretensōes educacionais e algumas variáveis sócio-econômicas e educacionais de sua família, que podem influenciar no seu desempenho escolar.

Em 1998, foram incluídos: 
$\checkmark$ o Questionário do Professor com o objetivo de conhecer a sua opiniaao sobre o contexto escolar, bem como obter informações sobre sua vida profissional e sua prática pedagógica.

$\checkmark$ o Questionário do Pai ou Responsável (Controlador de Qualidade) com a finalidade de obter informaçōes sobre aspectos gerais da Escola e avaliar a sua participação nas atividades escolares.

\subsection{Manuais de Orientação}

A coleta de dados sempre foi realizada mediante adoção de procedimentos e mecanismos detalhados em instrumentos de orientação, elaborados com a finalidade precípua de se ter uniformidade de ação no desenvolvimento das etapas de todo o processo de avaliação.

Esses manuais, elaborados pela equipe de Avaliação/SEE, contêm informaçōes específicas sobre cada função exercida e são destinados a nortear o desempenho das atividades dos grupos de trabalho, formados nos três níveis da administração: central, regional e local.

Outros manuais são também utilizados para orientar o trabalho de análise dos resultados da avaliação e de elaboração de Relatórios Finais, desenvolvido pela Escola (diretor, especialistas e docentes) tendo como finalidade garantir a homogeneidade da Avaliação em todo o estado, facilitar a consolidaçăo geral dos relatórios elaborados pelo Órgāo Central, contribuir para melhor compreensão dos dados estatísticos descritivos, bem como levar a uma reflexão a respeito dos pontos críticos diagnosticados e a uma atuação interveniente.

\section{Sensibilização e/ou incentivo para a prática de avaliar}

O trabalho de sensibilização teve início a partir da elaboração do Programa de Avaliação e consistiu inicialmente na apresentação desse programa à sociedade, de um modo geral, através das entidades de classes, sindicatos, para conhecimento e 
primeira divulgação, e foi se desenvolvendo durante o processo de Avaliação tendo sua culminância na disseminação dos resultados.

Para a comunidade Escolar sempre foram realizados dois treinamentos considerados como preparatórios operacionais:

$>$ primeiro ocorrendo sempre antes da realização de cada Avaliação e tendo como objetivo principal sensibilizar os técnicos das Superintendências Regionais de Ensino, os diretores de escolas, os professores, os alunos, enfim toda a comunidade escolar e repassar instruções específicas sobre cada Avaliaçăo, através de Manuais de orientação;

$>$ outro treinamento ocorrendo na fase de divulgação dos resultados, quando estariam sendo repassadas instruções para, após análise dos dados, serem elaborados os Relatórios Finais.

Participaram desses treinamentos elementos dos órgãos regionais que tiveram a incumbência de repassá-los para os órgãos locais. Esses treinamentos constituíram uma fase importante dentro de todo o trabalho, considerando o quantitativo de recursos humanos envolvidos (em torno de 60.000 profissionais por avaliação) e o pioneirismo da ação.

No percurso do trabalho algumas açōes permaneceram e foram contribuindo para o incentivo desta prática de avaliar. Dentre outras opçōes, destacam-se:

$>$ publicaçăo, em órgão oficial, de resolução própria para cada Avaliaçăo, especificando as instruçōes a serem seguidas em todo o Estado;

$>$ realização de reuniōes com associaçōes de classes, de pais de alunos, imprensa, etc;

$>$ utilização de materiais audiovisuais sobre Avaliação;

$>$ Envolvimento de todo o Sistema desde a fase inicial de cada Avaliação;

$>$ periodicidade na realização de Avaliação;

$>$ elaboração de documentos: "Desenvolvimento de Equipes em Avaliação do Ensino";

> criaçăo de um setor responsável pela avaliação - CEAVE, Centro de Qualidade de Avaliaçäo e Informação Educacional, 
encarregado do gerenciamento de todas as atividades referentes ao Programa;

$>$ realizaçăo de treinamentos operacionais para repasse de orientaçōes; participação de todos os segmentos em algum momento do processo;

- capacitação constante da equipe de avaliaçăo do órgão central e regional;

publicações de revistas e/ou relatórios de análises de resultados.

\section{Disseminação dos Resultados}

A Secretaria de Estado da Educaçăo de Minas Gerais, por meio da Diretoria de Avaliação do Ensino/Centro de Qualidade de Avaliação e Informação Educacional - DAVE/CEAVE sempre divulgou, após cada experiência avaliativa, os resultados por SRE, por Município e por Escola, bem como o resultado geral do Estado. Coube as SRE informar os resultados aos Municípios, Escolas, Professores, Colegiados e Comunidade a elas jurisdicionados.

O plano de difusão e disseminação dos resultados sempre fez parte da Avaliação desde o início e requer um processo de sensibilização, de informação, de distribuiçăo oportuna de resultados, de interpretação e uso dos mesmos, (Himmel, 1993). Decidir "o que", "a quem" e "como" informar é tarefa que deve delimitar o desenvolvimento e o processo de todo o Programa. Considerando que os resultados da avaliação devem fornecer informação útil e significativa, ser de interesse público e proporcionar soluções de melhoria, deve-se realizar uma ampla divulgação dos mesmos em todo o Estado, para que toda a comunidade os conheça. Os informes oferecidos proporcionam uma descrição dos aspectos mais relevantes, oferecem indicadores da qualidade do trabalho, assim como identificam os pontos críticos que devem ser melhorados.

A Secretaria sempre manteve a sua filosofia de não estabelecer comparaçōes entre os participantes das avaliaçōes e sempre teve em mente a importância da coerência entre a 
avaliação e a ação, entre o resultado que a avaliaçāo oferece e a atitude tomada - AVALIAR PARA AGIR.

\section{Conclusão}

Concluindo, pode-se dizer que a implantação do Programa de Avaliação da Escola Pública de Minas Gerais, numa perspectiva integrada e participativa de toda a comunidade educacional, começa a se efetivar, o que é evidenciado a partir dos ganhos, que podem ser considerados após análise do contexto no Estado. Hoje, o surgimento de uma cultura de avaliação começa a ser observado e a incorporaçāo dos resultados na formação de políticas e no planejamento do ensino já é uma realidade.

Em decorrência dos resultados obtidos nas experiências já realizadas, as escolas, os órgăos regionais e a própria Secretaria de Estado da Educação já podem planejar melhor e consolidar as metas básicas da educação.

Entre elas destacam-se:

- melhor uso do dinheiro público que é aplicado na Escola;

- treinamento de recursos humanos, planejados conforme evidências detectadas por região;

- distribuição de materiais pedagógicos e equipamentos conforme necessidade das escolas;

- mudanças necessárias nos currículos para meihorar o aprendizado dos alunos;

- participação dos pais nas escolas, cada dia mais efetiva.

Após a realizaçăo dessas experiências do Programa, a avaliação educacional passou a ser o fundamento do processo decisório no Estado, na medida em que propicia à Escola Pública a correção de rumos e as mudanças da realidade.

Neste período a DAVE/CEAVE assumiu papel estratégico para elevar os padrōes de qualidade do ensino no Estado, por meio de produção de informaçōes estatísticas e sondagens sistemáticas sobre a realidade da educação que se constituem, hoje, a base de um processo de avaliação permanente. 
As dimensōes e ramificaçōes desse trabalho geraram uma árvore de grande porte que poderá variar a sua copa conforme a situaçăo, a história dos envolvidos e até mesmo a compreensão que a comunidade e a sociedade como um todo tiveram dos benefícios que podem advir de um programa de avaliação sistemático, coerente e efetivo, para o futuro da educação no estado.

Já que resultados de avaliaçōes do porte do Programa de Minas Gerais geram sempre novos desafios, se Minas percorreu um caminho certo, e se os professores acolheram a idéia do potencial de contribuiçōes de uma avaliação de qualidade para aperfeiçoar/melhorar a aprendizagem de seus alunos, esses professores poderão assumir o papel de liderança e dar o toque de continuidade da avaliação implantada no Estado, independente de ser ou não obrigatória. 
PROGRAMA DEAYALIAĞ̄O DA ESCOLA PÚBLICA DE MINAS GERAIS ASPECTOS DIFEREACIADORES

\begin{tabular}{|c|c|c|}
\hline 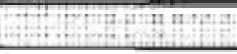 & 1? MOMENTO & $2^{\circ}$ MOMENIO \\
\hline $\begin{array}{l}\text { NAJWAEHA } \\
\text { DA } \\
\text { AVAI.IACAO }\end{array}$ & 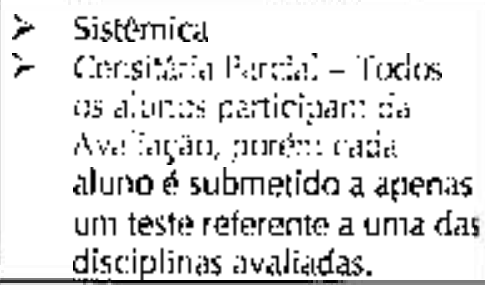 & 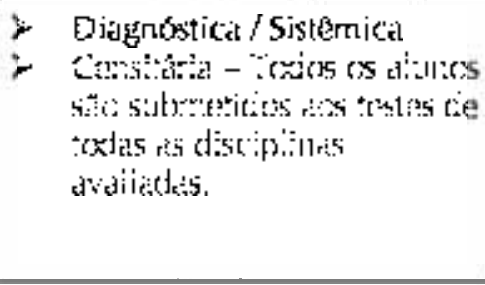 \\
\hline OBJETIVO & 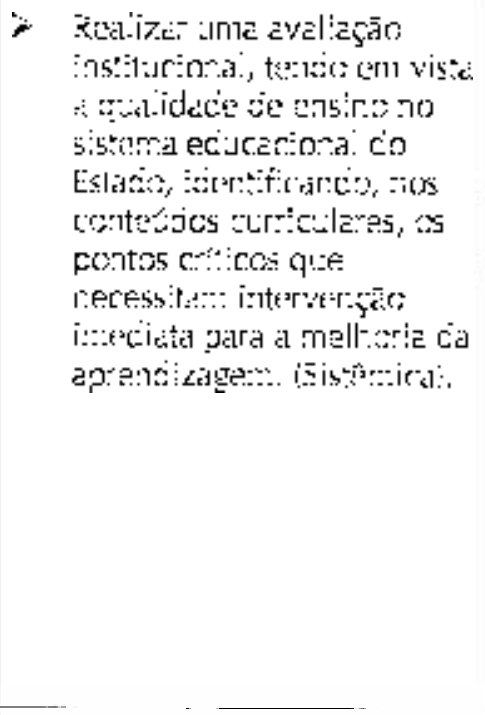 & 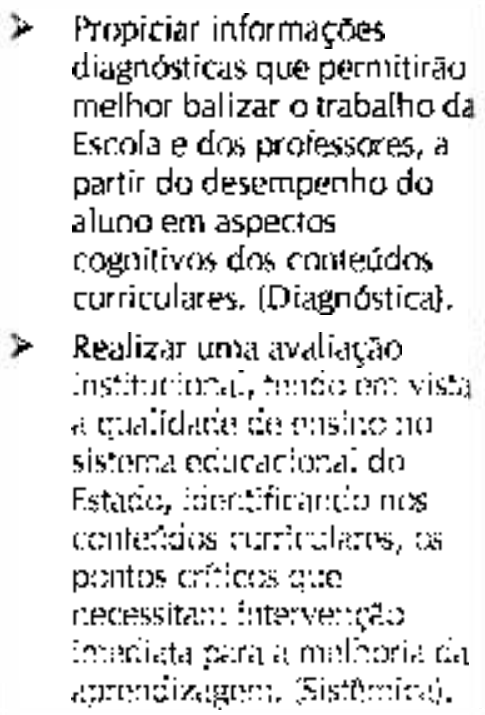 \\
\hline $\begin{array}{c}\text { POPULAGAO } \\
\text { ALWO }\end{array}$ & 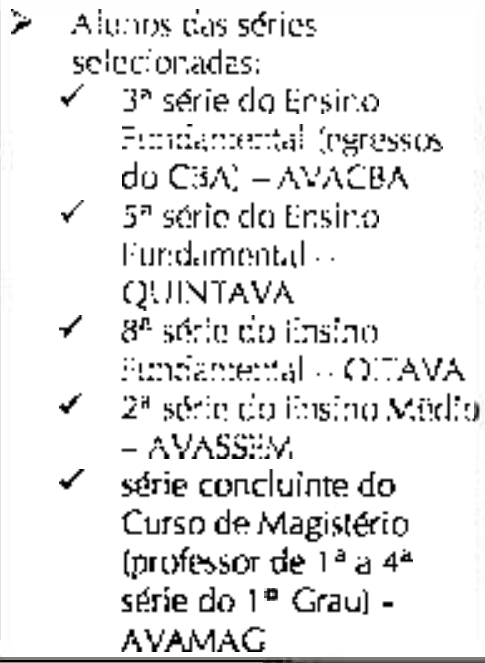 & 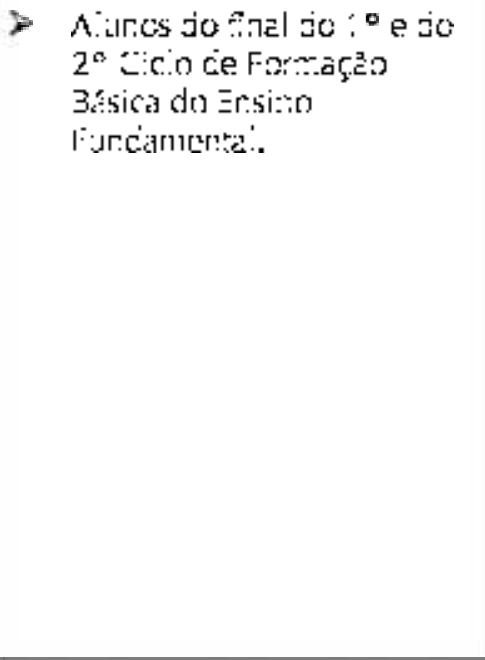 \\
\hline
\end{tabular}




\begin{tabular}{|c|c|c|c|}
\hline$\cdots$ & & $1^{\circ}$ MOMENTO & 20 MOMiLIIO \\
\hline $\begin{array}{c}\text { JSTRLIMENTOS } \\
\text { DE } \\
\text { AYALIAGÁO }\end{array}$ & & 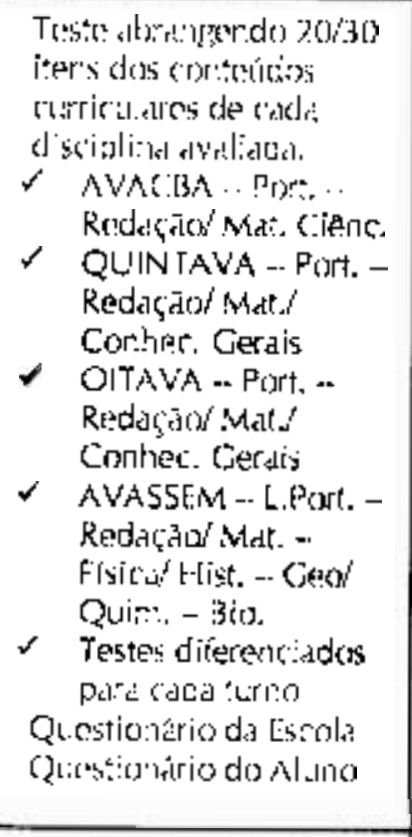 & 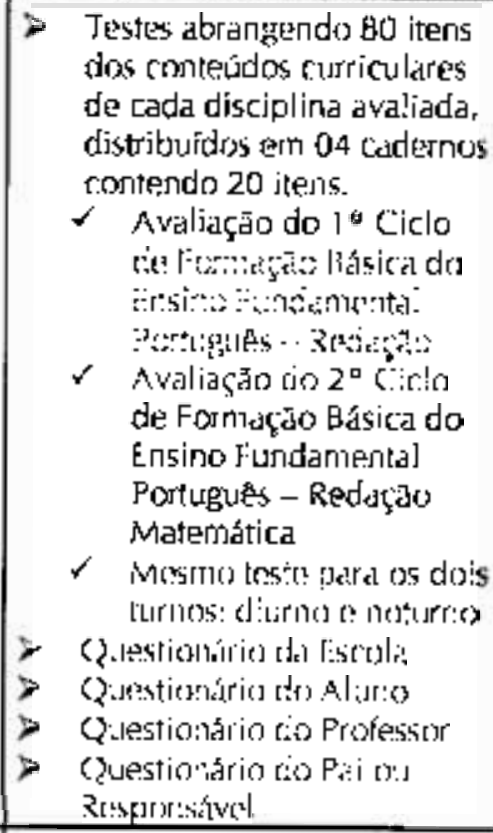 \\
\hline $\begin{array}{l}\text { TURMAS } \\
\text { AVALIADAS }\end{array}$ & $>$ & 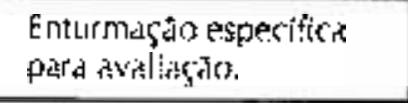 & 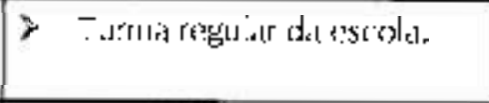 \\
\hline APAICADORES & & 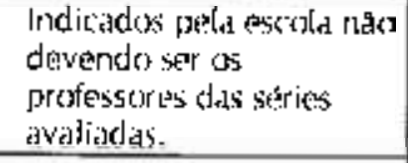 & $\begin{array}{l}\text { Os mewros professores das } \\
\text { turmas a seren avaliadas. }\end{array}$ \\
\hline $\begin{array}{l}\text { DATAIHOKAKAOO } \\
\text { DA APLICACÁO }\end{array}$ & $>$ & 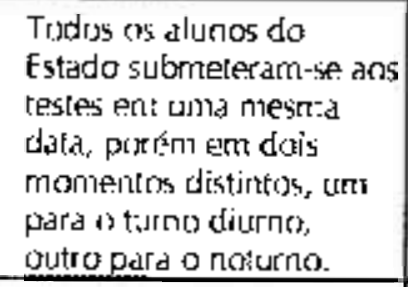 & 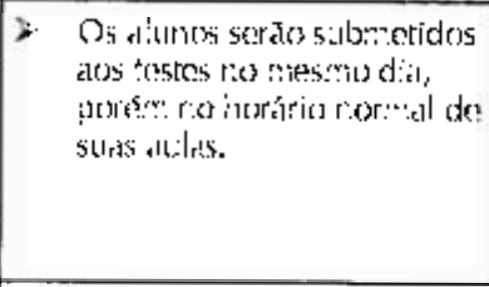 \\
\hline $\begin{array}{c}\text { TABELAS } \\
\text { ESTATISTICAS }\end{array}$ & $>$ & 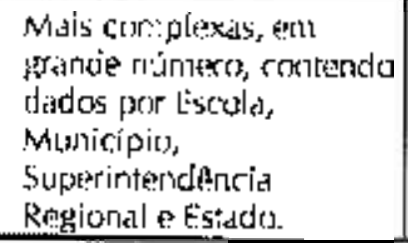 & 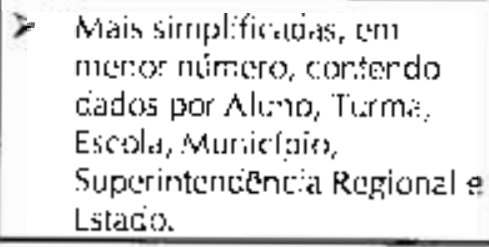 \\
\hline
\end{tabular}




\section{Referências Bibliográficas}

ANTUNES, A. L.; SOUZA, M. A. A escola e a comunidade escolar na avaliação da escola pública de Minas Gerais IDÉIAS, Sistema de Avaliação Educacional - Editora FDE Fundaçāo para o Desenvolvimento da Educação, n 30 - SP, 1998.

HIMMEL, E. Medición de los resultados educativos: el caso de Chile. Paper apresentado no Seminário sobre Procedimento Educacional. Secretaria de Estado da Educação de Minas Gerais, em Ouro Preto - MG, 1993.

POPHAM, W. J. Avaliação Educacional. Rio de Janeiro: Editora Globo, 1993.

VIANNA, H. M.; ANTUNES, A. L.; SOUZA, M. A. Desenvolvimento de um programa de avaliação do Sistema estadual de ensino: o exemplo de Minas Gerais. Estudos em Avaliação Educacional. São Paulo, n 8, jul./dez., 1993. 